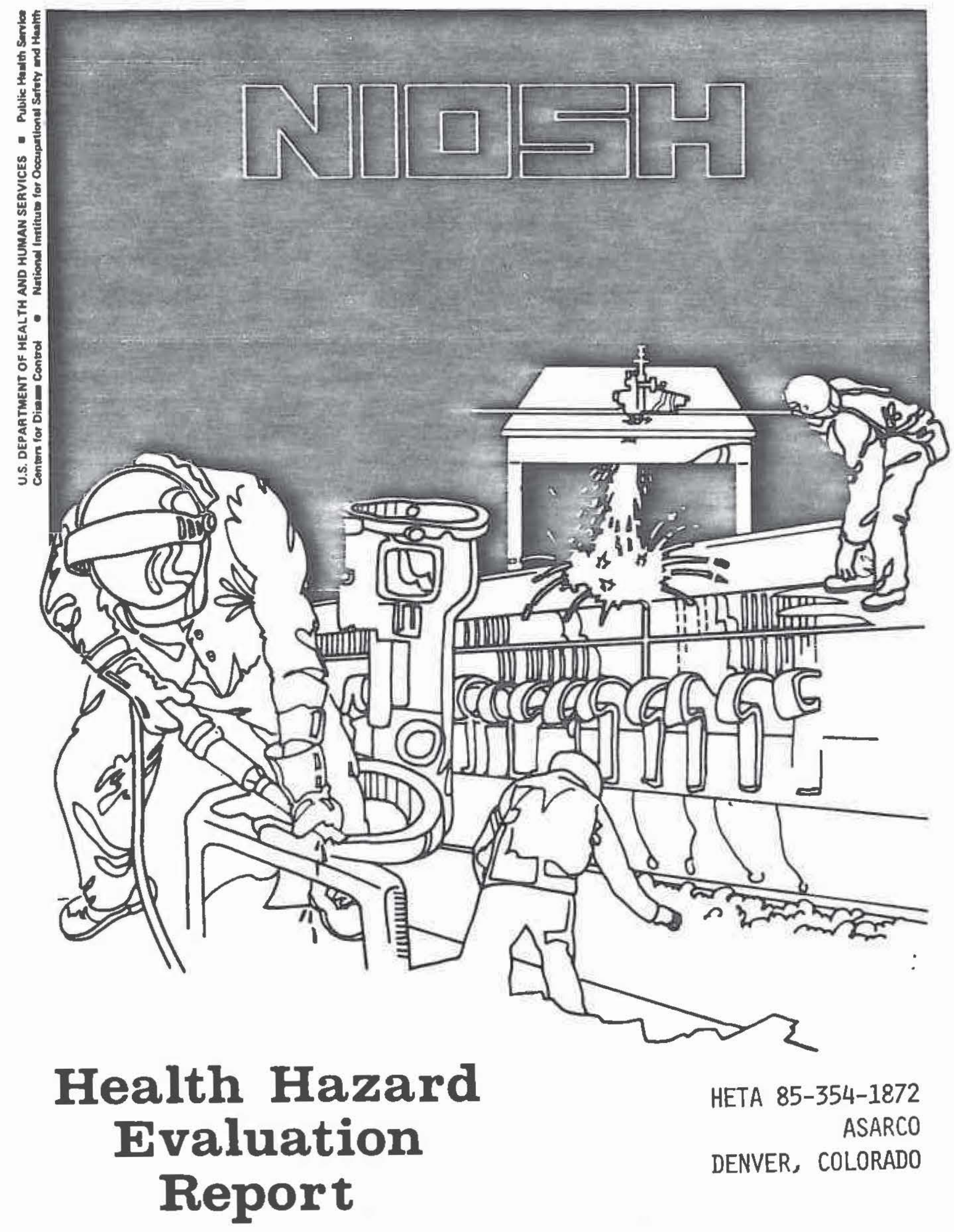


The Hazard Evaluations and Technical Assistance Branch of NIOSH conducts field investigations of possible health hazards in the workplace. These investigations are conducted under the authority of Section 20(a)(6) of the Occupational Safety and Health Act of 1970, 29 U.S.C. 669 (a)(6) which authorlzes the Secretary of Health and Human Services, following a written request from any employer or authorized representative of employees, to determine whether any substance normally found in the place of employment has potentially toxic effects in such concentrations as used or found.

The Hazard Evaluations and Technical Assistance Branch also provides, upon request, medical, nursing, and industrial hygiene technical and consultative assistance (TA) to Federal, state, and local agencies; labor; industry and other groups or individuals to control occupational health hazards and to prevent related trauma and disease. 
HETA 85-354-1872

February, 1988

ASARCO

DENVER, COLORADO
NIOSH INVESTIGATORS:

Michael J. Thun, M.D. Ana Maria Osorio, M.D. Susan Schober, Ph.D.

I. SUMMARY

In May 1985, Local 557 of the United Steelworkers Union requested that the National Institute for Occupational Safety and Health (NIOSH) evaluate health effects due to cadmium exposure at the ASARCO, Globe plant in Denver, Colorado. Although workers at this plant have participated in previous medical and epidemiological studies of health effects due to cadmium, the union asked NIOSH to evaluate the current status of kidney abnormalities.

NIOSH Investigators visited the plant in November 1985 and conducted a medical study of kidney function in 45 current and former cadmium production workers. The cadmium workers were compared to 35 male hospital workers of similar age, and ethnic and geographic background.

In the statistical analyses, each worker's cadmium exposure (cumulative exposure to airborne cadmium) was estimated from individual work histories and from air measurements collected by the company in each department from 1940-85. These exposure estimates were adjusted for respirator usage. Cadmium exposure was then related to kidney function to assess exposure-disease relationshlps.

The medical study found that kidney abnormalities were more common and more severe in the cadmium workers than in the hospital workers. Abnormalities of proximal tubular function included reduced reabsorption of beta-2-microglobulin ( $B-2)$, retinol binding protein (RBP), calcium and phosphate. Glomerular dysfunction was manifest as elevated serum creatinine. All of these measures of kidney function worsened with increasing cadmium exposure, even after controling for age, blood pressure and other factors in multivariate statistical analyses.

Although none of the kidney abnormalities are immediately life threatening, clinically signiflcant elevations of serum creatinine ( 2 $1.8 \mathrm{mg} / \mathrm{dI}$ ) were apparent in three cadmium workers, and low serum phosphorous ( $2.5 \mathrm{mg} / \mathrm{dl}$ ) in four. Both subclinlcal kidney abnormalities and overt kidney disease became more common as cadmium exposure increased. These changes were still apparent in workers who had not been exposed to cadmium for decades, indicating that cadmium-induced injury reverses slowly if at all.

Multiple abnormalities of tubular and glomerular function were apparent in workers whose cumulative cadmium exposure exceeded 300 $\mathrm{mg} / \mathrm{m}^{3}$-days. This exposure corresponded to working for only 4.3 years at $200 \mathrm{ug} / \mathrm{m}^{3}$, the official Occupational Safety and Health permissible exposure limit for cadmium dust. 
Based on these results, the NIOSH Investigators conclude that occupational overexposure to cadmium has caused kidney disease in workers at the ASARCO, Denver plant. Although exposures have been reduced, the levels in some departments are still sufficlently high to cause nephropathy. NIOSH recommends that exposures to cadmium in any form be restricted to the lowest concentration feasible, well below concentrations of $200 \mathrm{ug} / \mathrm{m}^{3}$ present inside the respirators of workers in some departments of the ASARCO Denver plant. Such a reduction is also indicated because of evidence that cadmium should be treated a potential human carcinogen. Recommendations regarding medical monitoring are presented in Section VIll of the report.

Keywords: SIC 3339, SIC 3333, cadmium, kidney disease, renal toxicity, nephrotoxicity. 
Page 3 - Health Hazard Evaluation Report No. 85-354

II. IXTRODUCTIOX

In May 1985, Local 557 of the United Steelworkers' Union asked rIOSH to evaluate health effects due to cadnium at the ASARCO Globe plant, in Denver, Colorado. Workers at this plant had participated in several previous medical studies evaluating kidney and lung function.[1-7] In addition, a subgroup of these workers are enrolled in a long-term mortality study comparing causes of death in cadmium workers with that in the U.S. population. $(8,9]$ The union asked uIOSH to conduct the present study to evaluate the current status of kidney abnormalities and to explain the significance of these findings to individual workers.

The Globe plant recovers cadmium from "bag house" dust, a waste byproduct of nonferrous smelters. Exposures to airborne cadmium were extremely high in the past, as indicated by air measurements obtained regularly by the company since the $1940^{\circ} \mathrm{s}$ (Table 1). Because of the extensive exposure data, the medical study also provided an opportunity to assess the quantitative relationship between exposure to airborne cadmium and various markers of renal tubular and glomerular function.

UIOSH investigators visited the plant in November 1985 and conducted the medical study. Workers were informed of their individual test results in March, 1986. NIOSH investigators met with company and union representatives in April, 1986 and discussed a mechanism for further medical followup for any workers with abnocmal findings who requested further testing.

III. BACKGROURD

Since 1925 the plant has recovered cadmium from "bag house" dust, a byproduct of nonferrous smelting. The details of the process have been described previously. ${ }^{(4-7)}$ In brief, dust contalning cadmium and smaller amounts of copper, selenium, thallium, arsenic, and indium was, until 1983, roasted, calcined, and processed electrolytically to recover cadmium. The cadmium was further refined in separate buildings into metal, or highly purified particulate oxide and sulfide. Other metals were separated out in either the roasting or electrolytic processes but were not further refined at this plant. Litharge, or technical grade lead oxide, was processed intermittently in a separate building by one to two workers.

Cadmium, ss either dust or fume, was the predominant exposure at the plant, although other metals were present.

Industrial hygiene measurements of atmospheric concentrations of cadmium have been obtained by the company since 1940. These data were previously compiled through $1976,[4-7]$ and were used to estimate each worker's cumulative exposure to cadmium, as described below. 
Page 4 - Health Hazard Evaluation Report No. 85-354

IV. STUDY DESIGM AND KETHODS

The study was a cross-sectional medical survey comparing measures of kidney tubular and glomerular function in current and fottner cadmium production workers with hospital workers of similar age, ethnicity, and geographic background.

Participants - The target population included all (19) active production workers and all (27) highly exposed former workers who were alive, residing locally, and reachable by telephone. Eligible former workers were identified from a master list of employees previously included in a retrospective cohort mortality study. [9] Participation among current cadmium production workers was $17 / 19$ (89\%) and among highly exposed fortuer workers was $18 / 27$ (67\%). In addition, two salaried workers and 8 former short-term production workers not in the target population also participated. A total of 45 cadmium workers were included.

The unexposed population consisted of male workers currently employed at a local hospital, who had never worked at the cadmium plant. The non-exposed participants were frequency matched on age to the cadmium workers. Non-exposed workers were initially recruited from the maintenance department ( 12 workers), and shipping and food service (7). Older unexposed subjects were subsequently recruited from office workers (6) and professionals (7). Thus, thirty-two unexposed workers participated.

Data Collection - The study consisted of a questionnaire, measurement of height, weight, and blood pressure (by a single examiner), collection of a "spot" daytime urine and serum sample, and pulmonary function testing. The questionnaire collected information about characteristics such as age, history of diabetes, hypertension, prostatic disease, phenacetin usage, smoking, and occupational and recreational exposures to cadmium, lead, and solvents.

Biological markers were selected to assess several types of renal dysfunction. Indices of renal tubular function include urinary excretion of B-2-microglobulin (B-2), retinol-binding protein (BBP), calcium, and phosphate. Markers of renal tubular injury (recent cellular damage) include the urinary enzymes $U$-acetyl glucosaminidase (NAG), alanine aminopeptidase (AAP), and gamma glutamyl transferase (GGT). Measurements reflecting glomerular function are serum creatinine (which increases as glomerular filtration rate decreases) and urine albumin (which increases either with abnormal glomerular permeability to macromolecules or with impaired tubular function). [10]

Laboratory methods - Serum and urine B-2 were measured by radioimune assay (Pharmacia, Piscataway, UJ, 1986), RBP by radial imutunodiffusion (LC-Partigen, Behring Diagnostics, LaJolla, CA), total calcium by modified o-cresolphthalien, creatinine by modified Jaffe method, serum albumin by bromocresol dye binding, and serum 
Page 5 - Health Hazard Evaluation Report Ho. 85-354

alkaline phosphatase by p-nitrophenylphosphate (Dupont, aca, discrete clinical anglyser, Wilmington, DE), inorganic phosphorous by Dupont aca autoanalyser, urinary enzymes AAP and GGT by COBAS BIO centrifugal analyser, [11] UAG by modified fluorimetric assay, [12] blood lead by atomic spectroscopy, [13] blood cadmium by graphite furnace atomic absorption, and urine cadmium by a modification of the method of Pruszkowska. [14]

Data transformation - To standardize for variations in serum concentration and urine volume, we expressed 8-2 and RBP excretion both as ug/gram creatinine and as fractional excretion. [15] The latter provides the best measure of the degree of tubular impairment, and is computed as (urine B-2/plasma B-2) / (urine creatinine/plasma creatinine). Albuminuria is expressed as mg albumin/mg creatinine, as proposed by Ginsberg and others. $[16,17]$ Tubular reabsorption of phosphate (XTRP) and of calcium (XTRC) are used to express the tubular handling of these substances, and are computed as the product of (1 fractional excretion) $\times 100$. Body mass is expressed as the puetelet index [weight $(\mathrm{kg}) /$ height $(\mathrm{m})^{2}$ ]. Body surface area $\left(\mathrm{m}^{2}\right)$ is computed as [weight $(\mathrm{kg}) 0.5378 \times$ height $(\mathrm{cm}) 0.3964 \times 0.024265$ ]. [18]

\section{Estimation of Exposure}

To estimate each worker's cumulative exposure to airborne cadmium, we used the industrial hygiene measurements obtained by the company for the various departments from 1940-1985. These data had already been compiled through 1976.[3-7] Using the same methods and assurptions and more recent company exposure measurements, we extended the matrix through 1985 (Table 1). We then linked the detailed work history for each subject with the exposure matrix, multiplying the number of days a worker spent in a given department/time by the estimated exposure level $\left(\mathrm{mg} / \mathrm{m}^{3}\right)$ in that department/time. The sum represents the worker's cumulative external exposure or dose and is adjusted for respirator use as described by Smith et, al.[6]. Briefly, the geometric mean concentration of cadmium in air in all 8-hour TWA breathing zone measurements was computed for the relevant time period. Respirator usage was assumed to reduce the actual inhaled cadmium concentration by $74.36 \%$ in departments in which respirators were used regularly. The respirator protection factor was determined by Smith et. al. in a survey that measured cadmium concentrations inside and outside of respirators at the Globe plant. [6] We also measured cadmium in blood and urine, and lead in blood. All of these variables were considered as possible determininants of renal function in the statistical analyses.

Statistical analyses - Variables with a skewed distribution were logarithmically transformed to approximate the normal distribution. student's $t$ test was used to test the difference between gfoup means for continous variables, and chi-square to test association between dichotomous variables. Potential confounders were included in regression analyses if associated with both exposure and outcome at p<8.1. Stepwise multiple linear regression was used to identify those 
Page 6 - Health Hazard Evaluation Report No. 85-354

independent variables and two-way interaction terms that best. explained each of the renal outcomes of interest. Logistic regression was used to determine the probability of renal outcomes being "abnormal" at various exposure levels, when abnormal was defined by the geometric mean in the unexposed minus two standard deviations (for \% TRC and \% TRP) or plus two standard deviations (for B-2, RBP, and creatinine).

\section{v. EVALUATION CRITERIA}

No attempt was made to measure current airborne exposures to cadmium or other metals. Rather, the analysis used exposure data obtained by the company to examine the prevalence of renal disorders in relation to cumulative exposure to airborne cadmium. A time-weighted average of $200 \mathrm{ug} / \mathrm{m}^{3}$ was used as a reference value in some analyses, since this is the official Occupational Safety and Health Administration (OSHA) permissible exposure limit (PEL) for cadmium dust in air. 119] Interim protection measures, proposed by OSHA in December 1987 call for a limit of $50 \mathrm{ug} / \mathrm{m}^{3}$ for cadmium dust or fume in air. [20] NIOSH has proposed that cadmiun exposure be reduced to the lowest extent feasible. The NIOSH recommendation is based upon human and animal data suggesting that cadmium should be controlled as a potential human carcinogen. [21]

\section{RESULTS}

We observed several demographic differences between the cadmium exposed and comparison populations (Table 2). The cadmium workers were slightly older (mean age $54 \mathrm{v} . \mathrm{s}$. 50 years, $p=0.2$ ), and more likely to be Hispanic ( $58 \%$ v.s. $16 \%$ p<0.0001). The exposed workers were shorter and heavier than the unexposed, resulting in a significantly higher mean Quetelet index (174.4 v.s. 155.4, $p=.0014)$. Fewer of the cadmium workers were current smokers (38\% v.s. $44 \%, p=.6)$, and of those who had ever smoked, they had consumed fewer pack years on average (14.6 v.s. $22.1, p=.29)$.

Measures of exposure to cadmium and lead are also included in Table 2. Blood cadmium concentrations were significantly higher in the exposed workers than in the unexposed ( $7.9 \mathrm{v.s} .1 .2 \mathrm{ug} / \mathrm{dl}, \mathrm{p}<.0001)$, as was urine cadmium ( 9.3 v.s. 0.7 ug/gram creatinine, p<.0001). The average blood lead concentration was also higher in the cadmium workers than in the unexposed ( $11.9 \mathrm{v.s} .8 .3 \mathrm{ug} / \mathrm{dl} p=.0013$ ). The highest current blood lead was $32.6 \mathrm{ug} / \mathrm{dl}$.

Several medical conditions were reported more commonly by the cadmium workers than by the unexposed. These include kidney stones ( $18 \%$ v.s. $3 \%, p=.07)$, prostatic disease $(20 \% \mathrm{v} . s, 6 \%, p=.09)$, diabetes $(18 \%$ v.s. $3 \%, p=.07$ ), and hypertension (38\% v.s. 16\%, $p=.03$.$) . All of$ these differences between the exposure groups were evaluated as potential confounders or intermediate variables in subsequent rultivariate analyses. 
Page 7 - Health Hazard Evaluation Report No. 85-354

Blood pressure measurements are presented in Table 3 . The cadmium workers had significantly higher systolic (134 v.s. $120 \mathrm{~mm} / \mathrm{Hg}$, $\mathrm{p}=.0004$ ) and diastolic ( $80 \mathrm{v.s} .73 \mathrm{~mm} / \mathrm{Hg}, \mathrm{p}=.0019$ ) blood pressure than the unexposed. Eight cadmium workers and three controls had diastolic blood pressures above $90 \mathrm{~mm} / \mathrm{Hg}$ (Fisher's Exact $p=.35$ ). Eleven cadmium workers and two controls had systolic blood pressures above $150 \mathrm{~mm} / \mathrm{Hg}$ (Chi-square $=4.4, p=0.036$ ).

The lung function data were not analysed statistically, in part because the relatively greater smoking habits of the unexposed workers eclipsed potential adverse effects of cadmium in the small study group. The individual results were reported to the study participants.

Indices of renal function are shown graphically in Figure 1 and sumnarized numerically in Table 3 . Tubular dysfunction appears in a subgroup of cadmium workers as increased urinary excretion of B-2 and BBP, and decreased tubular reabsorption of calcium and phosphate (Figure 1). Wo evidence of enzymuria, reflecting recent necrosis of tubular epithelium, is seen in the cadmium workers. Glomerular dysfunction is manifest as a small increase in mean serum creatinine. Urinary albumin excretion is higher in the cadmium workers than in the unexposed, but the increase is mild and could reflect either a pure tubular or a mixed tubular and glomerular albuminuria. One exposed worker had an albumin/creatinine ratio of over $0.2 \mathrm{mg} / \mathrm{mg}$. The value for this person $(0.23 \mathrm{mg} / \mathrm{mg})$ was substantially below the ratio of $\geq 3.5$ observed in nephrotic syndrome. (16)

Table 3 shows that the excretion of B-2 and RBP is higher in the cadmium workers when expressed as either urine concentration (ug/gram creatinine) or as fractional excretion (Table 3 ). Thus, the increased excretion of these proteins reflects renal tubular dysfunction, not simply increased serum concentrations. Excretion of B-2 is highly correlated with other indices of kidney dysfunction. Correlation coefficients between B-2 (ug/g creatinine) and other markers are as follows: RBP $(R=0.91, P<.0001)$, 2TRP ( $R=-.63$, $p<.0001)$, XTRC $(R=-.53, P<.0001)$, and serum creatinine ( $R=.51$, $\mathrm{p}<.0001$ ).

Clinically significant abnormalities are clustered in the ten cadmium workers whose urinary 8-2 excretion exceeds 1000 ug/gram creatinine. For example, 3 (30\%) of these have serum creatinine $\geq 1.8 \mathrm{mg} / \mathrm{dl}, 4$ (40\%) have serum phosphorous below $2.5 \mathrm{mg} / \mathrm{dl}$, and 4 (40\%) have \%TRP $<65 \%$, whereas $0 / 32$ unexposed workers had similar abnormalities. Mildly elevated serum alkaline phosphatase ( $>170$ International Units) was measured in $3 / 10$ cadmium workers with the highest B-2, versus $1 / 32$ unexposed. 
Page 8 - Health Hazard Evaluation Report No. 85-354

\section{Hultiple Regression Analyses}

Hultiple regression is used to determine which variables best explain the renal tubular and glomerular outcomes. Curmulative exposure (dose) was chosen as the exposure variable, because, in our data, it correlates more closely with the renal outcomes than does urine cadmium. We also included age, systolic and diastolic blood pressure, Hispanic ethnicity, months since last exposure to cadmium, Quetelet index, body surface area, history of hypertension, prostatic disease, diabetes, and blood lead concentration.

Renal outcomes- Figure 2 shows the data points, the regression line, and the $95 \%$ upper and lower confidence intervals for the models best explaining B-2, RBP, KTRC, KTRP, and serum creatinine. Table 4 presents the actual regression models. The diagrams in Figure 2 consider only variables that are significant at the $p<.05$ level. Those models that include age (RBP and $2 T R C$ ) are illustrated with age arbitcarily fixed at the mean age of the population ( 52.6 years).

Dose is the single most important variable associated with all of the renal outcomes. Consistent with a renal tubular toxin that impairs reabsorption of B-2, B.BP, calcium, and phosphate, cadinium dose is positively associated with tubular proteinuria (B-2, BBP) and negatively associated with XTRC and KTRP. Dose is also positively associated with serum creatinine, consistent with a glomerular effect. Cadmium dose explained $50 \%$ of the variance of $B-2,45 \%$ of RBP, $27 \%$ of KTRC, $23 \%$ of serum creatinine, and $18 \%$ of XTRP. When B-2 and $\mathrm{RBP}$ are reexpressed as fractional excretion (FE), dose is again the single most important predictor (Table 4, footnote). The association between dose and B-2 diminished slightly when B-2 was expressed as fractional excretion.

Time since last exposuce to cadmium was not an important determinant of any renal outcome, either by itself or a modifier of cadmium dose. Host of the workers with very high B-2 excretion had not been exposed for several years. For example, 9/15 (60\%) cadmium workers with the highest B-2 excretion had not been exposed to cadmium for at least five years, and one for 45 years.

We looked particularly closely at whether the higher serum creatinine in the cadmium workers might be explained by a known risk factor such as age, diabetes, prostatic disease, or hypertension, rather than cadmium. The relation between cadmium dose and serum creatinine persisted even when we excluded from the analysis all persons with current diastolic blood pressure $\geq 90 \mathrm{~mm} / \mathrm{hg}$, systolic pressure $\geq 150$ $\pi \mathrm{m} / \mathrm{hg}$, or positive history of diabetes, prostatic disease, or hypertension, while controlling for age, ethnicity, and blood lead (coefficient for dose $\times 10^{-4}=.476, p=.0007$ ). We also tested whether kidney stones might provide a mechanism linking cadmium to increasing serum creatinine by excluding subjects with kidney stones 
Page 9 - Health Hazard Evaluation Report No. 85-354

from the regression analysis. The coefficient for dose remained essentially unchanged $\left(0.34\right.$ v.s. 0.41 dose $\left.\times 10^{-4}\right)$, suggesting that the association between cadmiun and serum creatinine is not dependent on kidney stones.

To test whether extreme or outlying data points might distort the slope of any of these regression lines, we repeated the analyses in Table 3 after excluding the most extreme outliers. Outliers were excluded if the residual (observed value - predicted value) exceeded the 95th percentile. Exclusion of outliers had a neglible effect on the coefficient for dose for any of the renal endpoints. In all cases the $F$ value for dose remained highly significant. In the absence of a cogent reason to exclude the outliers, we present the full data.

Hypertension and albuminuria - Table and Figure 2 do not show the relation between cadmium dose and (a) systolic or diastolic blood pressure, or (b) albuminuria. Dose is a statistically significant predictor of systolic but not of diastolic blood pressure, after controlling for age, Quetlet index, ethnicity, and blood lead. As dose increases from 0 to $5000 \mathrm{mg} / \mathrm{m}^{3}$ days, mean predicted systolic blood pressure increases from 125.9 to $145.3 \mathrm{~mm} / \mathrm{Hg} \quad(\log \mathrm{SBP}=2.10+$ $.1246 \times$ dose $\left.\times 10^{-4}, p=0.04\right)$. Dose is also a statistically significant predictor of the urinary albumin/creatinine ratio, as are age and systolic blood pressure (log albumin [mg/mg creatinine] = $-5.22+1.250$ dose $\times 10^{-4}+8.54$ age $\times 10^{-3}+1.338 \times \log \mathrm{SBP}$, $p$ value for dose $=.0008$ ). The relation of albuminuria to dose does not clarify whether the urinary albumin reflects a-pure tubular or a mixed tubular and glomerular lesion.

Prevalence of renal abnormalities versus exposure

Figure 3 illustrates the probability of having various renal abnormalities vs. cumulative exposure to cadmium. The definitions of "abnormal" are specified in the legend for Figure 3, and are defined based on the unexposed workers. The prevalence of abnornalities increases with cumulative exposure to cadmium; multiple renal abnormalities become apparent in persons with cumulative exposure $\geq 300 \mathrm{mg} / \mathrm{m}^{3}$ days.

A similar analysis was performed using urine cadmium as the measure of exposure. To compare our data to those of Nogawa et. a1. [22] we adopted their definition of "abnormal" for urinary B-2 (>5 mg B-2/1iter). The probability of an abnormal $B-2$ was somewhat higher for a given level of urine cadmium in our study than in that of Vogawa. For example, a urine cadmium of $3.2 \mathrm{ug} / \mathrm{g}$ creatinine was associated with a $1 \%$ prevalence of abnormal B-2 in the Nogawa study, [22] versus $2.8 \%$ in ours. 
Page 10 - Health Hazard Evaluation Report No. 85-354

\section{DISCUSSION AND INTERPRETATILN}

The cross-sectional data presented here help to quantify the relation between cadmium exposure and several parameters of renal tubular and glomerular dysfunction. Increased cumulative exposure to cadmium (dose) is accompanied by increased low- and high-molecular weight proteinuria, reduced calcium and phosphorous reabsorption, and increased serum creatinine. While these data are cross-sectional rather than longitudinal, they provide an important link in the theoretical continuum between cadmium's subacute renal toxicity and more serious long term sequel.lae.

It is important to consider whether factors other than cadmium might explain the study results. Like most cross-sectional studies, our investigation is limited to surviving workers who reside locally and who agree to be tested. This could potentially introduce participation bias. However, it was our perception at the time of the study that non-participants included many older, ill workers who were reluctant to participate because of a snowstorm. The exclusion of these workers would cause us to under- rather than to over-estimate renal disease in the cadmium workers. Also, it seems improbable that participation bias alone could account for dose response trends for multiple renal outcomes. A second possible source of bias could result from demographic differences between the hospital workers and the cadmium-exposed workers. Table 2 indicates that there were differences between these two groups. However, even if the hospital workers were unusually healthy with respect to their renal function, this explanation would not explain why all measures of kidney function worsen among the cadmium workers with increasing cadmium exposure (Figure 2). Finally, one must consider whether exposures other than cadmium might account for the results. of the various metals and solvents used at the Globe Plant, cadnium and lead are the two putative nephrotoxins. $[4-5]$ Lead processing occurs in an isolated operation. Workers who staffed this operation were not those most severely affected in our study. In contrast, cadmium exposure was generalized throughout the plant and was intense, particularly in the past. The renal findings observed in the participants in our study are consistent with those described in other cadmium exposed populations, $[23-26,28\}$ again suggesting that cadmium is the most likely causal agent.

The extensive literature on cadmiun nephropathy suggests that at least two manifestations of renal dysfunction may be of particular clinical and public health importance. First, disturbed calcium-phosphorous metabolism, manifest in our study by phosphaturia, low serum phosphorous, and low tubular reabsorption of calcium are postulated to contribute to the bone disease and kidney stone formation observed in certain cadmium-exposed groups. $[23,24]$ Second, progressive loss of renal tubular function may cause, or be accompagnied by, a more subtle reduction in plomerular filtration rate (GFR) and increased serum creatinine. [2]] 
Page 11 - Health Hazard Evaluation Report No. 85-354

An epidemic of severe bone disease occurred in Japan among women consuming cadmium contaminated rice. [24,25] The syndrome was called "Itai Itai ("ouch ouch") disease and was manifest by bone pain, skeletal deformities, and spontaneous fractures. Even in villages where rice was heavily contaminated with cadmium, clinical osteopathy was confined to poorly nourished, postmenopausal women, suggesting that cadnium precipitated clinical disease in persons at high risk due to nutritional and endocrinologic factors. [24,25]

Similar bone disease has been rare in occupational populations. Bone pain and spontaneous fractures were reported in British and French alkaline battery workers near the end of World War 11.[25,26]. In general, however, male workers with adequate nutrition do not experience spontaneous fractures or radiologic abnocmalities, and female workers have not been studied longitudinally for the occurrence of osteopathy after menopause.

A second potential consequence of hypercalcuria or phosphaturia is susceptibility to kidney stones. Kidney stones are comon in cadmium-exposed populations, with lifetime prevalence reportedly ranging from $19 \%$ to $44 \%$. [23] In our study $8 / 45$ (18\%) of cadmium workers had experienced kidney stones, versus $1 / 32$ (3\%) of the unexposed. Several mechanisms could link stone formation to renal tubular disease, including hypercalcuria, phosphaturia, uricaciduria, reduced urinary citrate, or renal tubular acidosis. [27] The field techniques used in our study did demonstrate differences in calcium and phosphorous excretion associated in the cadmium workers, but they were not designed to be a complete clinical or metabolic evaluation.

Field investigators have generally been unable to study the effects of cadmium on glomerular filtration rate (GFR). Friberg, in Scandinavia, measured inulin clearance in 19 heavily exposed alkaline battery workers. GFR was below population normals in these workers, but the study could not control for age or relate inulin clearance to quantified exposure levels.[28] Adams found increased serum creatinine in nearly all of 23 workers with severe tubular : proteinuria. $[23,29]$ Our study is unique in relating increasing serum creatinine to quantified dose of cadmium. It is also, the first to use multivariate techniques to determine that cadmium, rather than age, hypertension, or other extraneous variables, best explains this relationship. Although serum creatinine is less sensitive than creatinine or inulin clearance as a measure of GFR, using serum creatinine as the marker of glomerular function is more likely to obscure a true association with cadmium than to create a false positive one. The theoretical possibility exists that cadmiun might increase serum creatinine by a tubular mechanism, selectively decreasing postglomerular secretion of creatinine by the nephron while sparing tubular reabsorption. However, we are unaware of any experimental studies of cadmium supporting such an interpretation. 
Page 12 - Health Hazard Evaluation Report \$o. 85-354

In some workers in our study evidence of tubular dysfunction persists for decades after the cessation of exposure to cadmium. Other investigators have noted that beta-2-microglobulinuria persists, and even increases in some workers after employment ceases. [23] The issue of the reversibility of nephropathy is controversial, however, partly because longitudinal data are rarely available, and partly because the assay for $B-2$ has increased in sensitivity over time. In our study, multiple tubular lesions were manifest in workers who had retired many years before. Furthermore, in multiple regression analyses, time away from cadmium did not appear to modify the association between cadmium dose and any measure of renal effect. These data suggest that if cadmium nephropathy is reversible, the recovery is so slow as to be undiscernable in our data set.

The significantly higher systolic and diastolic blood pressure in the cadmium workers, relative to the unexposed, is an interesting and potentially important finding. It resurrects a longstanding debate about whether cadmium can cause hypertension in humans. Hypertension has been observed experimentally in rats drinking

cadmium-contaminated water. [30] It has been sought, but rarely found, in studies of highly exposed workers. [31] A theory has been advanced that low doses of cadmium may increase, and higher doses may decrease, blood pressure in humans. [31] Blood pressure

measurements in our study were performed by a single examiner using one instrument. We did not anticipate an association between blood pressure and cadmium. Rather, we measured blood pressure as a factor to be controlled for in the analysis of serum creatinine. Deither a history of hypertension nor current blood pressure explained the relation between cadmium exposure and secum creatinine. This suggests that hypertension is not an extraneous factor causing an artifactual association between cadmium and serum creatinine in our data.

Estimating the "critical dose" of cadmium necessary to induce nephropathy depends upon both the choice of measures of renal effect and on the definition of abnormal. Our definitions of "abnormal" (Figure 3 ) are based upon the 5 th or 95 th percentile of test results in the unexposed population. The probability of abnotmality, by this definition, increases sharply as cumulative exposure to cadmium rises above $300 \mathrm{mg} /$ cubic meter days. Persons whose cumulative exposure exceeds this level frequently manifest multiple renal tubular abnotmalities, with elevated $B-2$ and RBP and low $\%$ TRC appearing at similar exposure levels.

A final question concerns whether current occupational standards protect against cadmium nephropathy. The "safe" level of cadmium clearly depends on the criteria for renal injury and the anticipated working lifetime. If $300 \mathrm{mg} /$ cubic meter days is judged to be "safe". based on the above reasoning, then this exposure is exceeded by working for 4.3 years at the current official OSHA permissible exposure limit of 200 ug/cubic meter for cadmium dust averaged over an B-hour workday. [19] Average exposure would need to be reduced 
Page 13 - Health Hazard Evaluation Report No. 85-354

by a factor of over ten to protect workers over a 45 year working lifetime. These results support a recommendation by a working group of the World Health Organization to limit exposures to 10 ug $/ \mathrm{m}^{3},[32]$

\section{RECOHMENDATIONS}

1. Exposures to cadmium at the Globe plant should be reduced to the fullest extent feasible. Various exposure limits have been proposed, including $10 \mathrm{ug} / \mathrm{m}^{3}$ TWA (World Health Organization) and $50 \mathrm{ug} / \mathrm{m}^{3}$ (interim protective limit proposed by OSHA. [20] This study suggests that the current of $f$ icial OSHA PEL of $200 \mathrm{ug} / \mathrm{m}^{3}$ is clearly insufficient to protect workers from renal effects over a 40-year working lifetime. NIOSH recommends controlling exposures to the lowest extent feasible, based on both nephrotoxicity and potential carcinogenicity. [21]

2. Reduction of exposure is particularly important in the retort department. Between 1980-85, company measurements indicate that exposures averaged $776 \mathrm{ug} / \mathrm{m}^{3}$ 8-hour TWA. Assuming that respirators in the retort department reduced actual exposures by $74.4 \%$. (survey of respirator efficacy at ASARCO) [6] then cadmium exposures in the retort department averaged $200 \mathrm{ug} / \mathrm{m}^{3}$ between 1980-85 (Table 1 ).

3. The current program of annual medical surveillance of ASARCo workers at the Globe plant should be expanded to include measurement of urinary B-2-ug and simultaneous urine creatinine and $\mathrm{pH}$. At the time of the NIOSH study, only serum B-2-ug was being measured. Serum B-2-ug provides no information about early cadmium renal injury. Urinary B-2-ug, adjusted for urinary creatinine, is presently the most readily available indicator of early cadmium nephropathy. Increased B-2-ug in a cadmium worker should be interpreted as evidence of cadmium-induced kidney injury unless an alternative explanation (lymphatic or hematologic cancer) is clearly identified. Urinary B-2-ug may be falsely low in urine samples with a pH below 5.5. Thus, in these unusual instances, either alkalinization of the urine or measurement of retinol binding protein, in addition to B-2-ug, is indicated.

4. Workers should receive copies of individual test results obtained during routine testing or special medical studies.

IX. REFEREWCES

1. Mational Institute for Occupational Safety and Health, Center for Disease Control, Public Health Service, HETAB Report \# 77-10, 1977.

2. Ellis KJ, Morgan WD, Zanai I, Yasumura S, Vartsky D, Cohn SH, In vivo measurement of critical cadmium level in human renal cortex. Am $J$ Ind Hed. 1:339-348, 1980. 
Page 14 - Health Hazard Evaluation Report Wo. 85-354

3. Ellis KJ, Cohn SH, Smith TJ. Cadmium inhalation exposure estimates: their significance with respect to kidney and liver cadmium burden. $\mathrm{J}$ Tox and Env Health. 15:173-187, 1985.

4. Smith TJ, Anderson RJ, Reading JC. Chronic cadmium exposures associated with kidney function effects. Am. J. Ind. Med. $1: 319-337,1980$.

5. Smith TJ, Petty TL, Reading JC, Lakshminarayan S. Pulmonary effects of chronic exposure to airborne cadmium. Am Rev Resp Dis. 114: $161-169,1976$.

6. Smith TJ, Ferrell WC, Varner MO, Putnam RD. Inhalation exposure of cadmium workers: effects of respirator usage. Am Ind Hyg Assoc J. $41: 624-629,1980$.

7. Smith TJ, Berrell WC, Verner MO, Putnam RD. Inhalation exposure of cadmium workers: effects of respirator usage. Am. Ind. Hyg. Assoc. J. $41: 624-629,1980$.

8. Lemen BA, Lee JS, Wagoner JK, Blejer HP. Cancer mortality among cadmium production workers. Ann. M.Y. Acad. Sci. 271:273-9, 1976.

9. Thun MJ, Schnorr TH, Smith AB, Halperin WE, Lemen BA. Mortality among a cohort of cadmiuta production workers-an update. JखCI. $74: 325-333,1985$.

10. Kjellstrom T. Renal effects. In: Friberg L, Elinder C, Kjellstrom T, Nordberg G, eds. Cadmium and health: a toxicological and epidemiological appraisal. Boca Raton, FL: CRC Press, 1986, Volume 2, 21-109.

11. Heller PW, MacNeil ML, Steinberg KK. Stabilization of alanine amimopeptidase, gamba glutamyltranspeptidase, and N-acety1-B-Dglucosaminidase activity in normal urines. Arch Environ Contam Toxicol 1986;15:343-347.

12. Leaback DH, Walker PG. Studies on glucosaminidase. 4. The

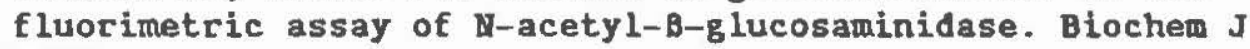
$1961 ; 78: 151-156$.

13. Paschal DC, Bell CJ. Improved accuracy in the determination of blood lead by electrothermal atomic absorption. Atomic spectroscopy $1981 ; 2: 146-150$.

14. Pruszkowska E, Carnrick GR, Slavin W. Direct determination of cadmium in urine with use of a stabilized temperature platfocm furnace and zeeman background correction. Clin Chem 1983;29:477-480.

15. Thun MJ, Clarkson TW. Spectrum of tests available to evaluate occupationally induced renal disease. J Occup Med 1987;28:1026-1033. 
Page 15 - Health Hazard Evaluation Report No. 85-354

16. Ginsberg JA, Chang BS, Matarese RA, et, al: Use of single voided sample to estimate quantitative proteinuria. N Engl J Med $1983 ; 309$ : 1543-1546.

17. Shaw AB, Risdon P, Lewis-Jackson JD. Protein creatinine index and Albustix in assessment of proteinuria. Br Med J 1983;287:929-932.

18. Haycock GB, Schwartz GJ, Wisotsky DH. Geometric method for measuring body surface area: a height-weight formula validated in infants, children, and adults. J Pediatr 1978;93(1), 62-66.

19. Code of Federal Regulations, U.S. Department of Labor, Occupational Safety and Health Administration, 29 CFR 1910.1000, Table Z-2 (1981).

20. U.S. Department of Labor, Occupational Safety and Health Administration, OSHA Instruction TUB B-4.1. Protective measures for controlling exposure to cadmium. Program directive to field staff. December 2, 1987.

21. National Institute for Occupational Safety and Health, Center for Disease Control, Public Health Service, Current Intelligence Bulletin 42, Cadmium (CD), DHHS (NIOSH) Publication No. 84-116, 1984.

22. Nogawa K, Kobayashi E, Honda R. A study of the relationship between cadmium concentrations in urine and renal effects of cadmium.

Environ Health Persp 1979;28,161-168.

23. Kjellstrom T. Renal effects. In: Friberg L, Elinder C, Kjellstrom T, Nordberg G, eds. Cadmium and health: a toxicological and epidemiological appraisal. Boca Raton, FL: CRC Press, 1986, Volume 2, 21-109.

24. Tsuchiya $\mathrm{K}$ Ed. Cadmium studies in Japan: a review. First Edition Elsevier/North-Holland Biomedical Press, Amsterdam 1978.

25. Kjellstrom $T$. Effects on bone, on vitamin $D$, on calcium, metabolism. In: Friberg L, Elinder C, Kjellstrom $T$, Nordberg $G$, eds. Cadmium and health: a toxicological and epidemiological appraisal. Boca Raton, FL: CRC Press, 1986, Volume 2, 111-158.

26. Adams RG, Harrison JF, Scott P. The development of cadmium induced proteinuria, impaired renal function, and osteomalacia in alkaline battery workers, Quart J Hed 1969;38(152):425-443.

27. Coe FL, Favus MJ. Idiopathic hypercalcuria in calcium nephrolithiasis. Disease of the Month 1980 Sep; 26(12):1-36.

28. Friberg L. Health hazards in the manufacture of alkaline acumulators with special reference to chronic cadmium poisoning. Doctoral thesis, Acta Med Scand $1950 ; 138$ (supl 240):1-124. 
Page 16 - Health Hazard Evaluation Report No. 85-354

29. Adams RG, Clinical and biochemical observations in men with cadmium nephropathy. A twenty year study, Arh Hig Rada Toksikol 1979;30: 219-231.

30. Schroeder $\mathrm{HA}$, Vinton WH. Hypertension induced in rats by small doses of cadmium. Aro J Physiol 1962;202: 515-518.

31. Elinder CG. Other toxic effects, In: Friberg $L$, Elinder $C$, Kjellstrom T, Nordberg G, eds. Cadmium and health: a toxicological and epidemiological appraisal. Boca Raton, FL: CRC Press, 1986, Volume 2, pg 160-179.

32. WHO, Recommended health-based limits in occupational exposure to heavy metals. Report of a study group, Tech. Rep. Ser. 647, world Health Organization, Geneva, 1980.

\section{$X$ AUTHORSHIP AND ACKNOWLEDGEMENTS}

Evaluation Conducted and

Report Prepared by:

Laboratory Assistance

Originating office
Michael J. Thun, H.D.

Chief, Epidemiology 11 Section

Industrywide Studies Branch

Ana Maria Osorio

Medical officer

Industrywide Studies Branch

Susan Schober, Ph.D

Epidemiologist

Industrywide Studies Branch

Brenda Lewis

Laboratory technician

Environmental Health Laboratory

Science,

Center for Environmental Health

Industrywide Studies Branch DSHEFS, MIOSH, Cincinnati 
Page 17 - Health Hazard Evaluation Report No. 85-354

\section{DISTRIBUTION AMD AVAILABILITY OF BEPOBT}

Copies of this report are currently available, upon request, from viosh, Division of Technical Services, Publications Dissemination, 4676

Columbia Parkway, Cincinnati, Ohio 45226. After 90 days, the report will be available through the National Technical Information Service (NTIS), Springfield, Virginia 22161.

Copies of this report have been sent to:

1. United Steelworkers Local 557

2. ASARCO Inc.

3. Colorado State Health Department

4. OSHA, Region Vill

For the purpose of informing the "affected employees", the employer shall promptly post the report for a period of 30 calendar days in a prominent place near where the exposed employees work.

The authors wish to thank Drs. Dennis Waite, Kathleen Kreiss and staff of the National Jewish Medical Center for providing a comparison population, the United Steelworkers of America for the examining facility, Ms. Brenda Lewis for laboratory assistance, and Drs. Gary Diamond, Robert Goyer, Theodore Meinhardt, Steven Teutch, and Richard Wedeen for their thoughtful review of the manuscript. 
TABLE 1

Estimates of Inhalation Exposures $\left(\mathrm{mg} / \mathrm{m}^{3}\right.$ ) By Plant Department and Time Perlod*

\section{Time Period}

Department Pre-1950 $\quad 1950-54 \quad 1955-59 \quad 1960-64 \quad 1965-79 \quad 1980-85$

\begin{tabular}{|c|c|c|c|c|c|c|}
\hline Sampling & 1.0 & 0.6 & 0.6 & 0.6 & 0.6 & 0.03 \\
\hline Roaster & 1.0 & 0.6 & 0.6 & 0.6 & 0.6 & -- \\
\hline Mixing & 1.5 & 0.4 & 0.4 & 0.4 & 0.4 & 0.07 \\
\hline Calcine & 1.5 & 1.5 & 1.5 & 0.4 & 0.15 & 0.4 \\
\hline Solution & 0.8 & 0.8 & 0.4 & 0.4 & 0.04 & 0.04 \\
\hline Tankhouse** & 0.04 & 0.04 & 0.04 & 0.02 & 0.02 & 0.04 \\
\hline Foundry & 0.8 & 0.1 & 0.1 & 0.1 & 0.04 & 0.04 \\
\hline Retort & 1.5 & 0.2 & 0.2 & 0.2 & 0.2 & 0.2 \\
\hline Pigment & 0.2 & 0.2 & 0.04 & 0.04 & 0.04 & 0.08 \\
\hline Nonproduction** & 0.09 & 0.05 & 0.04 & 0.024 & 0.02 & 0.007 \\
\hline Office \& Lab & 0.005 & 0.004 & 0.004 & 0.003 & 0.003 & 0.003 \\
\hline Non-Plant*** & 0.09 & 0.05 & 0.04 & 0.04 & 0.02 & 0.02 \\
\hline Generai Labor & 1.166 & 0.485 & 0.485 & 0.331 & 0.279 & 0.041 \\
\hline
\end{tabular}

* Original estimates from $\operatorname{Smith}(4)$; data on non-production and non-plant exposures added by Ellis. (3) Exposures from $1980-85$ added by us based upon plant records and the assumptions of Smith(4)

** Plant departments not directly involved in production of cadmium (maintenance in shop, laundry, litharge, indium, thallium, Janitor, zinc, supervisory in plant, selenium).

*** Job classifications with reduced exposure conditions (guard, tallings dump, general labor outside plant buildings). 
Table 2

Selected Characteristics of 77 Study Participants

1

Cadmium

Wozkers

Unexposed

Number in Study

45

32

Personal Characteristic

Age (Mean \pm S.D.)

$54.4 \pm 15.5$

$50.1 \pm 13.0$

Percent Hispanic

$58 \%$

$16 \%$

Quetelet Index

$174.4(28.7) \quad 155.4(20.0)$

(Mean \pm S.D.)

Percent Current Smokers

$38 \%$

$44 \%$

Pack-years Smoked

$14.6(19.8)$

$22.1(29.4)$

(Mean \pm S.D.)

\begin{tabular}{|c|c|c|}
\hline $\begin{array}{l}\text { Years of Cadmium Work } \\
\text { (G.M., range) }\end{array}$ & $19(1-38)$ & 0 \\
\hline $\begin{array}{l}\text { Cumulative Exposure } \\
\left.\text { (mg } / \mathrm{m}^{3} / \text { days }\right)\end{array}$ & $604(0-5383)$ & 0 \\
\hline $\begin{array}{l}\text { Blood Cadmium (ug/d1) } \\
\text { (G.M. } \pm \text { S.D.) }\end{array}$ & $7.9 \pm 2.0$ & $1.2 \pm 2.0$ \\
\hline $\begin{array}{l}\text { Urine Cadmium } \\
\text { (ug/gram creatinine) } \\
\text { (Mean } \pm S \text { D.) }\end{array}$ & $9.3 \pm 6.9$ & $0.7 \pm 0.7$ \\
\hline $\begin{array}{l}\text { Blood Lead (ug/d1) } \\
\quad(\text { G.M., } \pm \text { S.D.) }\end{array}$ & $11.9 \pm 1.8$ & $8.3 \pm 1.4$ \\
\hline
\end{tabular}


TABLE 3

Measurements Related to Renal Function in the

45 Cadmium Exposed and 32 Comparison Workers

\begin{tabular}{|c|c|c|c|c|c|c|c|}
\hline \multirow[b]{3}{*}{ Outcome } & \multicolumn{3}{|c|}{ Exposed } & \multicolumn{3}{|c|}{ Unexposed } & \multirow[b]{3}{*}{ p-Value } \\
\hline & \multicolumn{2}{|c|}{ Geometric } & \multirow[b]{2}{*}{ Range } & \multicolumn{3}{|c|}{ Geometric } & \\
\hline & Mean & $(\mathrm{SD})$ & & Mean & $(S D)$ & Range & \\
\hline $\begin{array}{l}\text { Systolic B.P. (mm/Hg) } \\
\text { (G.M. } \pm \text { S.D.) }\end{array}$ & 134 & $(1.14)$ & $108-178$ & 120( & $(1.14)$ & $94-160$ & 0.0004 \\
\hline $\begin{array}{l}\text { Diastolic B.P. } \mathrm{mm} / \mathrm{Hg} \\
\text { (G.M. } \pm \text { S.D.) }\end{array}$ & 80 & $(1.13)$ & $64-102$ & 73( & $(1.13)$ & $58-92$ & 0.002 \\
\hline Beta-2-microglobulin & & & & & & & \\
\hline Serum (ug/L) & 2018 & $(2.0)$ & $887-10863$ & 1489 & $(1.3)$ & $954-2314$ & 0.008 \\
\hline Urine (ug/g creat.) & 470 & $(4.4)$ & $98-107143$ & 190 & $(1.6)$ & $81-565$ & 0.0001 \\
\hline Fractional excretion (\%) & 0.35 & (441) & $.03-17.5$ & 0.13 & (153) & $.065-.26$ & 0.0001 \\
\hline Retinol binding protein & & & & & & & \\
\hline Serum (mg/dl) & 5.4 & $(1.2)$ & $3.6-8.1$ & 5.1 & $(1.2)$ & $3.6-8.9$ & 0.23 \\
\hline Urine (ug/g creat.) & 266 & $(7.3)$ & $0-113179$ & 88 & $(1.9)$ & $0-333.3$ & 0.0012 \\
\hline Fractional excretion (\%) & .006 & $(822)$ & $0-4.0$ & .002 & (194) & $0-.007$ & 0.001 \\
\hline Renal enzymes & & & & & & & \\
\hline NAG, urine (U/1) & 0.9 & $(3.6)$ & $0-15.4$ & 0.8 & $(2.3)$ & $0-4.3$ & 0.7 \\
\hline GGT, urine (U/I) & 13.0 & $(1.9)$ & $2.5-36.9$ & 17.9 & $(1.4)$ & $8.7-38.3$ & 0.008 \\
\hline $\mathrm{AAP}$, urine (U/I) & 7.2 & $(2.0)$ & $1.7-44.2$ & 6.1 & $(1.5)$ & $1.3-10.4)$ & 0.2 \\
\hline Creatinine, serum (mg/dl) & 1.16 & $(1.3)$ & $0.7-2.6$ & 1.01 & $(1.2)$ & $(0.7-1.4)$ & 0.006 \\
\hline $\begin{array}{l}\text { Albumin/creatinine } \\
\text { (ratio in urine, } \mathrm{mg} / \mathrm{mg} \text { ) }\end{array}$ & .017 & $(2.70)$ & $.002-.23$ & .009 & $(1.7)($ & $(.005-.05)$ & 0.0012 \\
\hline Calcium & & & & & & & \\
\hline Serum (mg/dl) & 9.7 & $(1.04)$ & $9.1-10.8$ & 9.7 & $(1.03)$ & $8.7-10.1$ & 0.69 \\
\hline Urine (mg/d1) & 11.2 & $(2.0)$ & $2.9-36.6$ & 10.5 & $(2.1)$ & $3.2-45.2$ & 0.69 \\
\hline Tubular Reabsorp.(\%) & 97.7 & $(1.02)$ & $92.9-99.6$ & 98.9 & $(1.01)$ & $96.7-99.8$ & 0.0002 \\
\hline Phosphorous, inorganic & & & & & & & \\
\hline Serum (mg/dl) & 3.2 & $(1.3)$ & $1.4-5.2$ & 3.7 & $(1.2)$ & $2.8-4.6$ & 0.002 \\
\hline Urine (mg/dl) & 33.4 & $(2.6)$ & $3-136$ & 61.3 & $(1.6)$ & $20-192$ & 0.006 \\
\hline Tubular Reab. (\%) & 78.1 & $(1.3)$ & $20-98$ & 83.2 & $(1.1)$ & $68.6-94.8$ & 0.139 \\
\hline
\end{tabular}


Table 4

Regression Models Best Explaining Renal Outcomes

Beta-2-Microglobulin ( $10 \mathrm{~g}$ ug/g creatinine)*

$\begin{array}{lllll}B & \underline{\mathrm{S}}, \mathrm{E} & \underline{\mathrm{F}} & \underline{\mathrm{R}^{2}}\end{array}$

$\begin{array}{llllll}\text { Intercept } & 2.323 & & & & \\ \text { Dose }\left(\times 10^{-4}\right) \star \star & 4.195 & 0.498 & 71.1 & <.0001 & 0.50\end{array}$

Retinol Binding Protein ( $\log \mathrm{ug} / \mathrm{g}$ creatinine)*

$\begin{array}{lllll}\text { B } & \underline{\mathrm{S}} \text {. } & \underline{\mathrm{R}^{2}}\end{array}$

$\begin{array}{llllll}\text { Intercept } & 1.457 & & & & \\ \text { Dose (x 10-4)** } & 3.657 & 0.6633 & 55.6 & <.0001 & 0.45 \\ \text { Age (Years) } & 0.010 & 0.005 & 4.2 & 0.044 & 0.03\end{array}$

Tubular Reabsorption Calcium ( $\log \%$ )

$\begin{array}{lllll}B & \text { S.E. } & \underline{\mathrm{F}} & \mathrm{D} & \underline{\mathrm{R}}^{2}\end{array}$

$\begin{array}{lllrll}\text { Intercept } & 1.999 & & & & \\ \text { Dose (x 10-4) ** } & -0.029 & 0.007 & 16.3 & 0.0001 & 0.27 \\ \text { Age (Years) } & -0.0001 & 0.00005 & 4.0 & 0.05 & 0.03 \\ \text { Diabetest } & 0.0044 & 0.0025 & 3.2 & 0.08 & 0.03\end{array}$

Tubular Reabsorption Phosphate ( $\log \%$ )

$\begin{array}{lllll}\text { B } & \underline{\mathrm{S}}, \mathrm{E} & \underline{\mathrm{R}^{2}}\end{array}$

$\begin{array}{lllrll}\text { Intercept } & 1.931 & & & \\ \text { Dose }\left(\mathrm{x} \mathrm{10^{-4 }}\right) \star * & -0.325 & 0.088 & 15.5 & 0.0002 & 0.18 \\ \text { Prostatic Diseaset } & -0.051 & 0.027 & 3.5 & 0.065 & 0.04\end{array}$

Serum Creatinine ( $\log \mathrm{mg} / \mathrm{dl}$ )

$\begin{array}{lllll}\text { B } & \text { S.E. } & \underline{\mathrm{F}} & \underline{\mathrm{R}}^{2}\end{array}$

$\begin{array}{lrrrrr}\text { Intercept } & 0.008 & & & & \\ \text { Dose (x 10-4)** } & 0.414 & 0.094 & 21.9 & 0.0001 & 0.23 \\ \text { Prostatic Diseaset } & 0.050 & 0.029 & 2.9 & 0.09 & 0.03\end{array}$

* Log FE $B-2=-2.82+3.08$ dose $\times 10^{-4}, \mathrm{R}^{2}=.38, F=44.4$

$\star$ Log FE RBP $=-5.35+3.58$ dose $x 10^{-4}+.01$ age, $\mathrm{R}^{2}=.45, F=56$

** Units of dose are $\mathrm{mg} / \mathrm{cubic}$ meter days

+ Diabetes or prostatic disease (by history) are indicator variables 
FIGURE 1

INDICES OF RENAL FUNCTION IN THE CADMIUM EXPOSED AND UNEXPOSED WORKERS
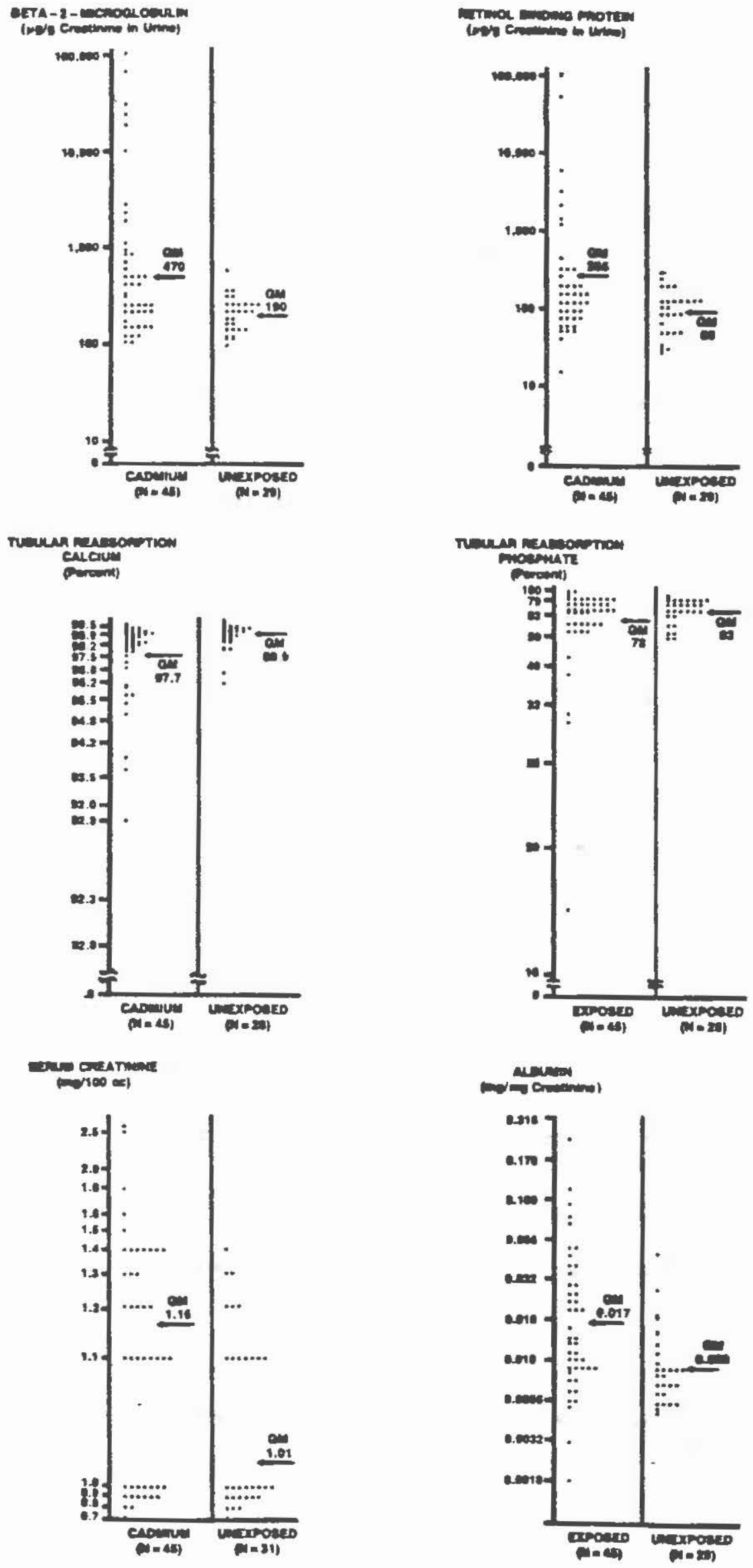


\section{FIGURE 2}

\section{Regression Of Various Renal Endpoints vs. Cadmium Dose*}
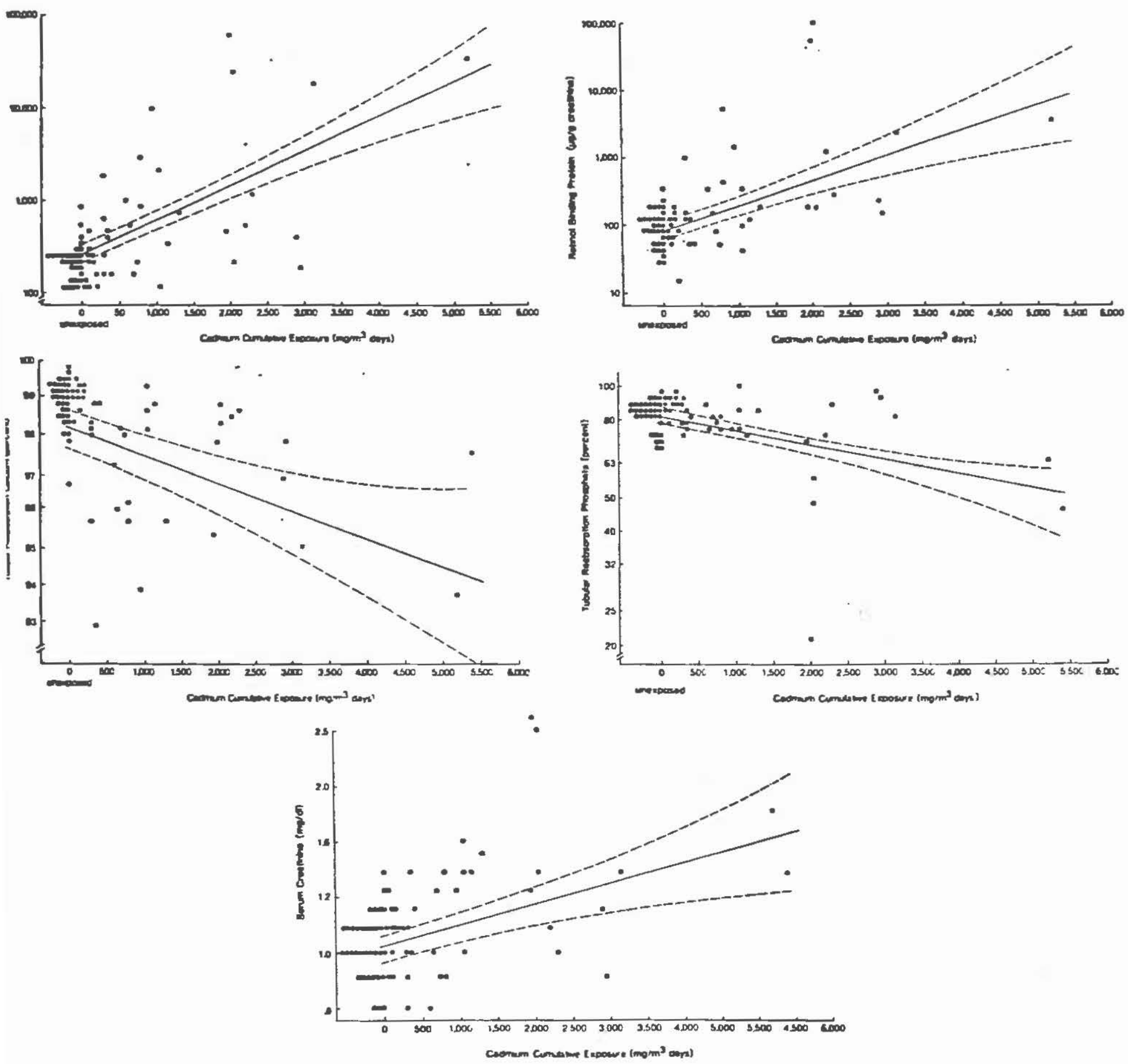

* Regression line models described in Table 4 
PROBABILITY OF RENAL ABNORMALTYY VERSUS CADMRM CUMULATIVE EXPOSURE

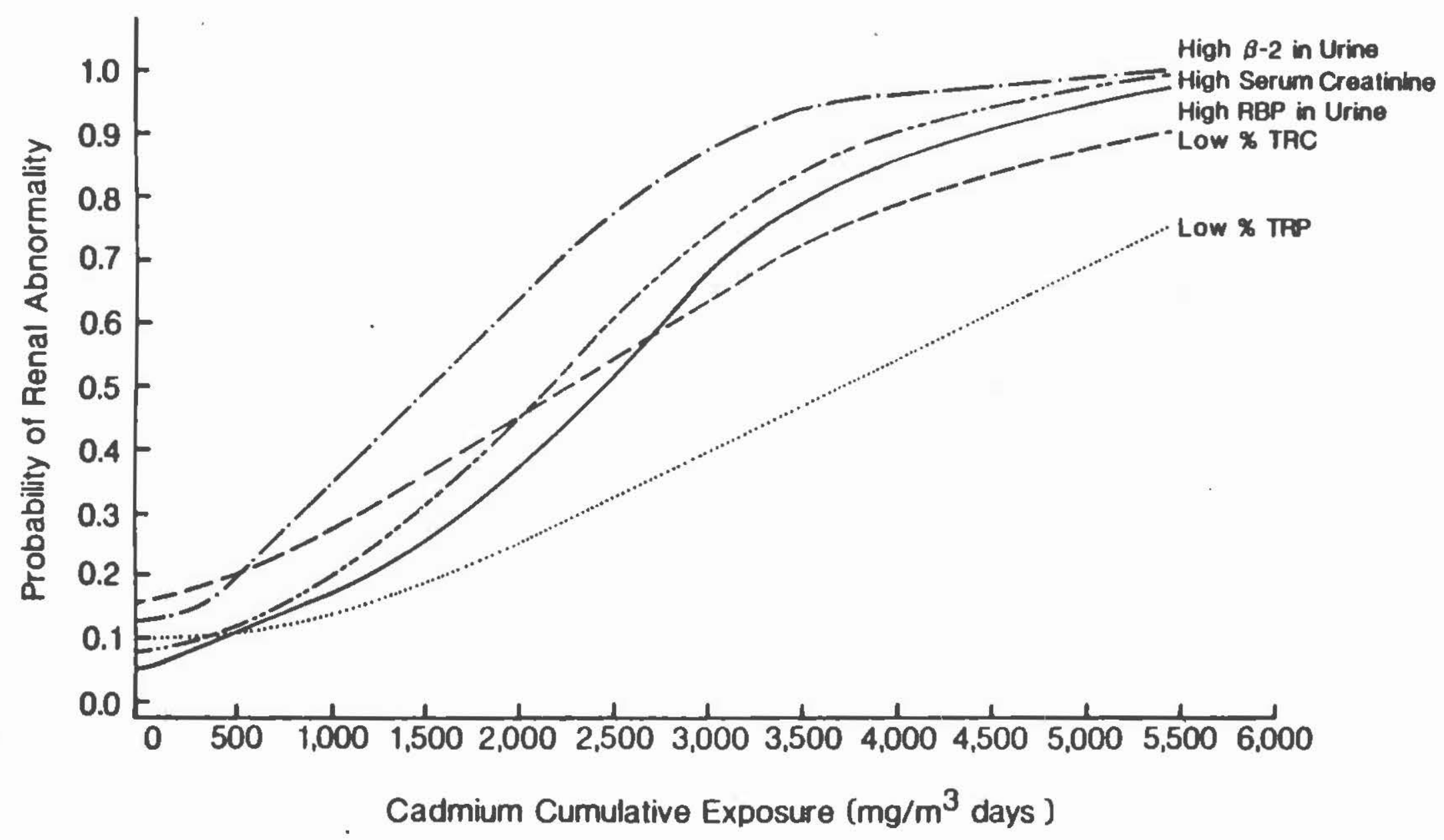

Footnote - Abnormal renal tests defined as follows: High $\beta-2>486 \mathrm{ug} / \mathrm{g}$ creatinine, high serum creatinine $\geq 1.4 \mathrm{mg} / \mathrm{dl}$, high RBP $>321 \mathrm{ug} / \mathrm{g}$ creatinine, low TRP $<69.4 \%$, 10W TRC $<97.56 \%$ 
DEPARTMENT OF HEALTH AND HUMAN SERVICES

PUBLIC MEALTH BEAVICE

CENTEAS FON DISEASE CONTROL

NATIONAL INSTITUTE FOR OCCUPATIONAL SAFETY AND MEALTM

ROBERT A. TAFT LABORATORIES

4670 COLUMEIA PAAKWAY, CINCINNATI, OHIO 48228

OFFICIAL OUSINESS

PENALTY FoR PAIVATE USE. 1000
Third Class Mail

POSTAGE AND FEES PAID

U.S. DEPARTMENT OF HHS HAS 395 